\title{
The disabled living centre: its relevance to rheumatology
}

\author{
M A Chamberlain
}

\begin{abstract}
When we describe ourselves as rheumatologists most of us have a clear idea of what we are and what we do, even if the reality is that we do not all do the same thing. The term disabled living centre does not produce an instant picture in the rheumatologist's mind. Yet many appreciate that such centres are of great value to their patients. Indeed, I have been approached regularly by colleagues who wish to set up, or help set up, such centres. This article is written in the hope that it may help such people, and whet the appetite of those previously unaware of the scope of a disabled living centre. Most will be familiar with the suggestion in the Royal College of Physicians' report 'Physical disability 1986 and beyond" that there should be a centre in every district.
\end{abstract}

\section{What is a disabled living centre?}

The Disabled Living Foundation was the first centre. It was founded in London, by Lady Hamilton in 1971. At that time there were many isolated responses to the disabled person's need for advice and information on technical equipment, which were individually helpful but uncoordinated. (The present situation is much the same with a vast range of information needed by disabled people but currently still in separate packets, as noted in the report of Coopers and Lybrand. ${ }^{2}$ ) At the Disabled Living Foundation a range of equipment for daily living was brought together and a library of information on equipment and other matters which disabled persons need was developed. The centre was so successful and so useful to disabled persons and the professionals helping them that others opened, both in the United Kingdom and abroad. There are now many disabled living centres (under various names) in the United Kingdom, including one in Belfast and three in Scotland. Most are permanent but a few consist of mobile units which tour rural areas. All centres that come up to agreed standards and wish it, are affiliated to the Disabled Living Centres Council, either as full or as associate members. All centres are independent of each other, but staff meet twice yearly and work together under the umbrella of the Disabled Living Centres Council. There are also thriving centres abroad-for example, Hong Kong, Australia, Paris. They are an important resource for patients which should be considered in the context of the need for a network of such resources appropriate to our patients. ${ }^{3}$

\section{What does a disabled living centre set out to do?}

The disabled living centre is really a resource centre for people with a variety of physical and sensory disabilities, including those of mobility, grasp and reach, visual impairment. There are over 11000 technical aids available so that it is quite impossible for any one occupational therapy department or indeed any individual doctor or therapist to have personal knowledge of more than a fraction of the products on the market and they will have to depend on catalogues or on visits to exhibitions, such as Naidex, to gain information on new equipment. As much equipment is also expensive it may be difficult to build up individual experience on its use in a particular disease or condition. Some pooling of information and some specialist expertise is an invaluable back up to the work done day by day in a rheumatology department. The centres have clear guidelines ${ }^{4}$ on their functions. Broadly these fall into two areas: to be available to give expert help to individual disabled people, their carers, and the professionals seeing them; and to be a centre of teaching and information. The Guidelines for the Establishment of a Disabled Living Centre ${ }^{4}$ lists 14 purposes of a centre ending 'any visitor should be able to leave a disabled living centre with relevant knowledge of the goods and services available to improve the quality of life of sick and handicapped people'.

\section{What are rheumatological patients likely to need from a disabled living centre?}

A recent survey highlights the fact that arthritis is the single most important disease group leading to disability and that the most common disability in adults in the United Kingdom is loss of mobility. ${ }^{5}$ There are thus huge numbers who might benefit from the centre's help. To this number we may add those with backache, who cannot lift with ease or garden, perhaps. Indeed many patients consider the frustration of the problems consequent on both degenerative joint disease and inflammatory joint disease as important as the pain from which they suffer.

In addition, we might bear in mind that in many rheumatology departments so brief are our outpatient appointments for older patients that many do not burden us with details of all their problems. When the Stanford health assessment questionnaire was used routinely, further problems related to poor function (and potentially to a disabled living centre) were
The General Infirmary Great George Street, Leeds LS1 3EX

M A Chamberlain 
found in $36 \%$ of our outpatient attenders already interviewed by rheumatologists. ${ }^{6}$

It is worth taking a look at a hypothetical patient with rheumatoid arthritis to illustrate how the centre may be of use. Let us assume that such a patient has polyarthritis in hands, wrists, knees, and feet, so that she may be unable to dress in reasonable time for work or for getting children off to school. She will probably have found that all seats, including the lavatory, are too low, that taps are usually turned off too tightly, and that she cannot turn the key in her front door. She may be experiencing difficulty in preparing foods, indeed in many domestic activities, in maintaining the family's clothing, in cooking, and in walking and shopping. Her part-time secretarial job may be in jeopardy.

When the patient telephones the centre for advice, which she may do without reference to her doctor, an appointment is given for about two weeks hence. The centre's experienced therapist allows for an appointment of at least one hour. She suspects that the query about taps hides a constellation of problems not indicated by the telephone conversation.

At the appointment the therapist takes the patient on a previously determined route through various sections of the centre. The patient would probably start in the kitchen and look at taps, sinks, tin openers, food processors, the suggestion being that normal labour saving devices are used whenever possible. In addition, many pieces of adapted cutlery are available, as well as equipment which makes cutting easier and puts less pressure on damaged joints, thereby reinforcing the principles of joint protection.

The patient will probably then look at bathroom equipment. Most patients do not require the expensive Closomat instead of a lavatory but many need a raised seat, rails placed strategically, a simple easily turned lock on the door. Many benefit from the Mangar bath seat which, having good trunk balance, they can use easily, but which is fairly costly. Some patients will have given up the idea of getting upstairs and are contemplating but dreading a move. Stairlifts are now regularly installed, and patients appreciate seeing a variety of makes. There may often be a delay of many weeks before installation by the local authority, however.

Substitution of one chair of a three piece suite by a vinyl covered steel-framed armchair provided by the social services department is unpopular and, nowadays, unnecessary. A variety of more homely or better upholstered armchairs with high seats and padded arms is available and some can be tailor made to individual requirements. Very comfortable, but expensive, motorised chairs are often on show also, but again correct assessment and careful guidance at the centre will help the patient select that which is most suitable.

Inflammatory synovitis might have taken its toll in the feet: the display usually includes tailormade and readymade shoes as well as clothing which is easy to don and doff, is in easily laundered materials, and of modern design. The standard crimpelene dresses of elderly women are no longer the only convenient attire suggested to patients. Individual designers and small firms can produce clothes which are very attractive, they can design trousers specifically for wheelchair occupants, and can teach others to make up clothes from basic patterns drawn up to individual requirements (however difficult or non-standard these are).

The centre often has a selection of wheelchairs from the Disablement Services Authority as well as outdoor electric chairs and scooters, which have to be bought privately by the user, and are expensive but invaluable. It often has displays from the Gas Board, Electricity Board, and British Telecom showing adaptations to the relevant equipment, and services provided by them. Advice is given on how to obtain such equipment.

It will probably have examples and details of call systems for vulnerable people living alone, intercoms, and door call equipment. There will be low vision aids, usually a modest selection of communications aids, sometimes a gardening section.

Our patient will almost certainly have needed the hour allotted to her and will have had valued expert advice given in an unhurried atmosphere. The suggestions for equipment are written down together with where they may be obtained. Further catalogues may be given. The patient will decide whether she wishes to purchase some articles (this cannot be done at the centre) or whether she wishes the community occupational therapist to be informed. The patient's doctor is not usually informed of the visit (unless $\mathbf{s}(\mathrm{he})$ sent a detailed letter to the centre) and some patients do not know their diagnosis. This may make it difficult for staff at the centre, who respect the patient's desire which may be not to go through the health service or social services department. Some patients come with their therapist, usually an occupational therapist, which improves communication greatly and often enables a more realistic assessment to be made.

\section{What other services are provided by a disabled living centre?}

It makes good sense not only to advise individuals but to alert professionals to the virtues of a disabled living centre. Occupational therapists are the professional group most likely to use the centres, doctors are much less likely. All may ask for seminars and workshops tailored to their requirements. Our centre has an open day each year when new equipment is on display. It has regular teaching sessions, and I have found it an excellent venue for informal, small courses for general practitioners on, for example, 'Arthritis in the home'. The lectures are interspersed with a tour of the centre, with which most were unfamiliar.

Disabled living centres often have a charitable status and maintain their independence and ability to innovate best in this way. They, therefore, have to make a small charge to professionals for teaching sessions. They never charge individual patients. 
Who uses disabled living centres?

It worries staff greatly that despite their considerable efforts to publicise their centre's usefulness many patients do not get referred for help. But first, what do we know of those who do come or telephone? Are they mainly casual inquirers or articulate middle class people who are adept at getting the advice and information they require?

Our research at the William Merritt Disabled Living Centre at Leeds suggested that they were neither (J Stowe, paper given at the Society for Rehabilitation and Research Conference, 1988). Stowe carried out two surveys of the telephone calls received by the Leeds disabled living centre in 1987 and again in $1988 .{ }^{7}$ In the second survey these were received from medical/paramedical personnel $(40 \%)$, carers $(23 \%)$, self referrals $(8 \%)$, and others (31\%), including education departments, manufacturers, retailers, and community services. Both studies showed that most patients who came already had moderate or severe disabilities and many

Table 1: Diagnoses of 65 visitors to the disabled living centre. (Reproduced with permission from $\mathrm{Br}$ Med $\mathcal{F} 1988 ; 297$ : 1523-6.)

\begin{tabular}{ll}
\hline Diagnosis & Nos of visitors \\
\hline Osteoarthritis & 15 \\
Rheumatoid arthritis & 7 \\
Multiple sclerosis & 7 \\
Respiratory related disease & 7 \\
Cerebral palsy & 5 \\
Cerebrovascular accident & 4 \\
Lower limb amputation & 4 \\
Ankylosing spondylitis & 2 \\
Parkinson's disease & 2 \\
Paraplegia & 2 \\
Problems related to eyesight & 2 \\
Laminectomy & 1 \\
Spina bifida & 1 \\
Muscular dystrophy & 1 \\
Poliomyelitis & 1 \\
Polymyositis & 1 \\
De Quervain's condition & 1 \\
Psoriatic arthritis & 1 \\
Hard of hearing & 1 \\
\hline
\end{tabular}

Table 2: Average score for ability of visitors to the disabled living centre. (Reproduced with permission from $\mathrm{Br} \mathrm{Med} \mathcal{J}$ 1988: 297: 1523-6.)

\begin{tabular}{ll}
\hline Activity assessed & Average score $^{*}$ \\
\hline Feeding & 9 \\
Toileting & 9 \\
Dressing & 8 \\
Cooking & 6 \\
Bathing & 6 \\
Leisure activities & 6 \\
Stairs & 5 \\
General mobility & 5 \\
\hline
\end{tabular}

$10=$ independent; $5=$ needs some help; $0=$ total dependency.

Table 3: Recommendations made for aids for disabled visitors to Leeds centre and outcome. (Reproduced with permission from $\mathrm{Br}$ Med $\mathcal{f}$ 1988; 297: 1523-6.)

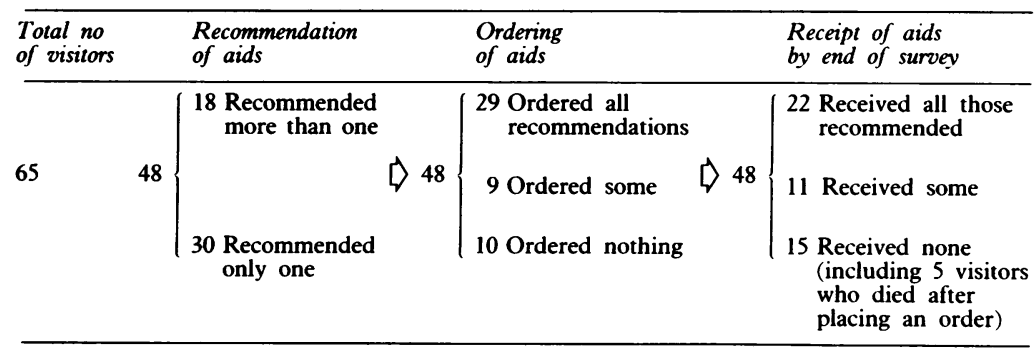

had arthritis (table 1). When we gave simple grades for ability in feeding, self care, etc the findings (table 2) were that these patients mirrored those in the OPCS survey ${ }^{5}$ to a considerable extent: they were fairly immobile and although few had difficulty in feeding or toileting, most were experiencing practical problems with dressing and with preparing food.

Their age reflected the incidence of disability, few were young, most were over 60 . But most came from less than 15 miles away, within a city with excellent road and rail connections. We thus conclude that health service staff (including rheumatologists) in other towns and cities in the region, were not referring patients. Why not? Wasn't it worth doing so? We asked the patients why they had come and the answer in $40 \%$ of cases was that they had a specific problem to solve.

Did it get solved? Of the 65 persons responding to the questionnaire, 48 were recommended at least one aid and 28 adaptations were also recommended (commonly a stairlift). Most patients did get what was recommended (table 3), though the delay was long in some cases (so long that we have no figures on the eventual outcome). The evidence is then, that those patients had a need which was capable of solution. This is supported by Aina's study of the Southampton disabled living centre, ${ }^{8}$ in which $98 \%$ of those recommended by the centre for aids or equipment were using them at the time of the survey. In 1988 when Stowe analysed telephone calls coming in to the Leeds centre she found that help was provided by this route alone to 10 of the 80 people telephoning to make an appointment.

Our study showed that doctors were rarely the primary source of referral, but perhaps they referred these patients to their local occupational therapist. Therapists were overwhelmingly the most common source of referral. General practitioners rarely referred patients, so that rheumatologists should not rely on this route. Indeed, in general, surveys (J Stowe, unpublished data) have shown that general practitioners recognise disease but rarely disability. This is perhaps not surprising given the lack of teaching of medical students.

\section{Setting up a disabled living centre}

Given the current shortage of funds in the National Health Service and the proposed profound changes in its organisation, it is not realistic to think that a health authority will now be keen to set up such a centre, though some, and some social service departments have done so in the past and have been most supportive of the staff and understanding of the centre's function.

A recent informal report showed that centres which were thriving, innovative, and best funded were in the main those which were independent charities with business status. Those supported by a larger organisation, such as a council for disabled people, were particularly fortunate, and those that had funding from several sources were most secure. 
There is much information and support available from the Disabled Living Centres Council, ${ }^{4}$ who now have a development officer with a particular brief to help new disabled living centres. But probably most important of all, a small band of knowledgeable and committed people must be convinced (rightly) that a centre is needed in their area. They must be prepared to fight for its establishment for several years; the group must have the ear (and backing) of crucial members of the local authority and health service. They must, between them, be prepared to wrestle with innumerable practicalities about which I have written in detail elsewhere, ${ }^{910}$ seek out a site, make initial moves, and obtain regular grants. They will need to refurbish the chosen centre, engage a manager and other staff, set up a management council, publicity committee, a band of volunteers, and a network of interested users. They will continue to be needed for many years.

Rheumatologists are used to such a time scale; they have experience of the handicaps many arthropathies bring and they are familiar with the concept of using many agencies, as well as drugs, to ameliorate their patients' handicaps. The disabled living centres have much to offer them-and, just as important, rheumatologists have much expertise of great importance to centre staff and councils. Both serve the same patients.

The author thanks those who have helped and advised in the writing of this paper: Mrs Sarah Tunstall, manager of the William Merritt Disabled Living Centre and vice president of the Disabled Living Centres Council, Mrs Janet Stowe, senior research occupational therapist, and Mrs Jackie Packter and Mrs B Glossop, who gave secretarial assistance.

The author is vice chairman of the Disabled Living Centres Council.

1 Anonymous. Physical disability 1986 and beyond. $\mathcal{f} R$ Coll Physicians Lond 1986; 20: 160-94.

2 Coopers and Lybrand. Information needs of disabled people, their carers and service providers. London: DHSS, 1988.

3 Fanshawe E. Resources available. In: Goodwill C J, Cham berlain $\mathrm{M} \mathrm{A}$, eds. Rehabilitation of the physically disabled adult. London: Croom Helm, 1988: 817-34.

4 Anonymous. Guidelines for the establishment of a disabled living centre. London: Disabled Living Centres Council, updated 1987.

5 Martin J, Meltzer H, Elliot D. OPCS surveys of disability in Great Britain. Report 1. The problems of disability among Great Britain. Report 1. The prob. London: HMSO, 1988.
adult

6 Young J Chamberlain M A. The contribution of the Stanford health assessment questionnaire in rheumatology clinics. health assessment questionnaire in rheum

7 Stowe J. Investigation into telephone inquiries made to the Leeds disabled living centre. British fournal of Occupational Therapy 1987.

8 Aina $\mathrm{O} O$. An evaluative study of an aid and equipment centre: reference to clients' satisfaction with level of independence (Dissertation). Southampton: University of Southampton, 1986.

9 Chamberlain M A, Gallop J. The disabled living centre: What does it do? $\mathrm{Br} M e d \mathcal{F}$ 1988; 297: 1523-6.

10 Chamberlain M A. Setting up and running a disabled living centre. International Disability Studies 1988; 10: 89-91. 